\title{
PAINÉIS DE PARTÍCULAS AGLOMERADAS DE MADEIRA DE Pinus elliottii Engelm., POLIESTIRENO (PS) E POLIETILENO TEREFTALATO (PET) ${ }^{1}$
}

\author{
Antônio da Silva Maciel $^{2}$, Benedito Rocha Vital ${ }^{3}$, Ricardo Marius Della Lúcia ${ }^{3} \mathrm{e}$ \\ Alexandre Santos Pimenta ${ }^{3}$
}

\begin{abstract}
RESUMO - O objetivo deste trabalho foi avaliar as propriedades de painéis fabricados com partículas de madeira, poliestireno (PS) e polietileno tereftalato (PET). Foram utilizadas três proporções, em relação à massa seca de madeira, de poliestireno (0, 25 e 50\%) e duas proporções de PET/PS (5/20 e 10/40\%), combinadas com 50, 75 ou $100 \%$ de partículas de madeira de Pinus elliottii. Os painéis foram produzidos com adesivos à base de uréiaformaldeído ou de fenol-formaldeído, em três teores $(0,4$ ou $6 \%$ ) e três níveis de solução de poliestireno em tolueno $(0,4$ e $6 \%)$, todos calculados em relação à massa seca total dos painéis. Foram produzidos painéis de aproximadamente 400 x 400 x $10 \mathrm{~mm}$, em camada única, com densidade aproximada de $0,6 \mathrm{~g} / \mathrm{cm}^{3}$. Determinou-se a resistência dos painéis à tração perpendicular à superfície, à flexão estática (módulos de ruptura (MOR) e elasticidade (MOE)), ao arrancamento de parafusos, bem como a absorção de água e o inchamento em espessura, após 24 horas de imersão. Todas as propriedades mecânicas dos painéis foram superiores às exigidas pela norma ANSI/A 208.1-1993. Contudo, todos os painéis absorveram água em valores superiores àqueles normalmente observados em painéis comerciais. Apesar disto, o inchamento em espessura foi compatível com o dos painéis de partículas de madeira existentes no mercado. Os painéis nos quais se aplicou a solução de poliestireno foram, de modo geral, os que apresentaram os melhores valores para todas as propriedades.
\end{abstract}

Palavras-chave: Painéis de partículas, poliestireno, polietileno tereftalato e solução de poliestireno em tolueno.

\section{PARTICLEBOARDS OF Pinus elliottii Engelm. WOOD, POLYSTYRENE AND POLYETHYLENE THEREPHTHALATE PARTICLES}

\begin{abstract}
This work aimed determine the properties of wood particleboards containing particles of polystyrene (PS) and polyethylene therephthalate (PET). Three amounts of polystyrene (0, 25 and 50\%), two amounts of PET/ $P S(5 / 20$ and 10/40\%), three amounts (0, 4 and $6 \%)$ of urea-formaldehyde or phenol-formaldehyde adhesive and three amounts of polystyrene in toluene solution (0, 4 and 6\%), combined with 50, 75 or 100\% of particles of Pinus elliottii wood were used. Layer boards measuring approximately $400 \times 400 \times 10 \mathrm{~mm}$ with density approximately equal to $0.60 \mathrm{~g} / \mathrm{cm}^{3}$ were produced. Internal bond, rupture and elasticity modulus, screw withdrawal, water absorption and thickness swelling after 24 hours of immersion were determined. The mechanical properties of all the boards were superior to the established by ANSI/A 208.1-1993 standard. All wood/plastic particleboards absorbed more water than those observed in commercial boards. However, the observed thickness swelling was quite similar to the values of commercial wood particleboards. Boards in which the solution of polystyrene was applied presented, in general, the best values for all the properties.
\end{abstract}

Key words: Particleboards, polystyrene, polyethylene therephthalate, solution of polystyrene in toluene.

1 Recebido para publicação em 1.7.2003 e aceito para publicação em 30.4.2004.

2 D.S. em Ciência Florestal, <antoniosmaciel@yahoo.com.>; ${ }^{3}$ Professor do Dep. de Engenharia Florestal da Universidade Federal de Viçosa - UFV, 36571-000 Viçosa-MG. 


\section{INTRODUÇÃO}

Painéis de partículas de madeira aglomerada são geralmente produtos fabricados com pequenos fragmentos de madeira ou outros materiais lignocelulósicos aglutinados com adesivos sintéticos ou outro aglomerante, sendo o conjunto prensado a quente por tempo suficiente para que a cura da resina se efetue. No Brasil, a madeira para produção de painéis aglomerados vem de florestas plantadas e de empresas produtoras, e entre estas algumas utilizam madeira de pinus na sua linha de produção, outras empregam apenas eucalipto e algumas combinam pinus e eucalipto em proporções variáveis. No mundo, $50 \%$ das indústrias deste produto empregam madeira de coníferas como matéria-prima principal, e outras empregam mais de uma espécie de madeira em suas linhas de produção (BNDES, 2000).

No País, os adesivos mais utilizados na produção de painéis de partículas de madeira aglomerada são os de uréia-formaldeído e fenol-formaldeído, além de outros aditivos como emulsão de parafina, retardantes de fogo e biocidas preservantes.

Embora a produção de painéis de madeira aglomerada já esteja consolidada em todo o mundo, novas matériasprimas e tecnologias de produção vêm sendo testadas para geração de novos produtos. Um dos materiais com grande potencialidade para ser associado à madeira, para produção de painéis, são as resinas termoplásticas. No Brasil, em 1999, foram produzidas cerca de 3,5 milhões de toneladas de resinas termoplásticas, e, desse total, mais de $65 \%$ foram destinadas às indústrias de embalagens plásticas (ANUÁRIO BRASILEIRO DO PLASTICO, 2000). Estas embalagens, após absorvidas pelo mercado consumidor, são descartadas como resíduo pós-consumo, e por não serem biodegradáveis tornam-se um sério problema ambiental. Este material, usualmente rejeitado, se recuperado poderia ser, em parte, utilizado como matériaprima para produção de compósitos termoplásticos.

Compósitos termoplásticos são produtos obtidos a partir de uma matriz, contínua ou descontínua, de resina termoplástica reforçada com partículas de madeira. Os produtos assim obtidos associam as melhores qualidades de cada constituinte e se caracterizam por apresentar propriedades peculiares, como baixa massa específica, grande estabilidade dimensional e grande resistência à corrosão, o que os distinguem de outros materiais.

Geralmente os compósitos termoplásticos são produzidos pelos processos de extrusão, injeção e compressão.
A tecnologia de produção dos compósitos termoplásticos reforçados com fibras lignocelulósicas utiliza, atualmente, como matérias-primas principais, em função de sua maior disponibilidade e adequação aos sistemas de produção, que requerem a fusão do material, os plásticos polietileno de alta e baixa densidade e o polipropileno em mistura com farinha e fibras de madeira e agentes compatibilizadores (English et al., 1996). Entretanto, durante a fusão destes polímeros recicláveis o calor afeta negativamente a maioria de suas propriedades. Por isto, na tentativa de manter inalterada suas estruturas, novos tipos de plásticos e processos de produção têm sido avaliados, para elaboração de materiais à base de plástico/ madeira. Dentre eles o poliestireno (PS) e o polietileno tereftalato (PET), que por suas características de dureza e disponibilidade têm se mostrado potencialmente capazes na produção de painéis de compósitos, obtidas por compressão.

No entanto, a maior parte dos trabalhos publicados (Bregner et al., 1988; Han et al., 1989; Yan et al., 1990; Simonsen et al., 1998, Wanage et al., 1998) teve como objetivo estabelecer as características de produtos fabricados com uma matriz de matéria plástica reforçada com fibras de madeira. Em apenas alguns trabalhos, como naqueles publicados por Youngquist (1992) e Oksman \& Clemons (1998), foi estudado o efeito da incorporação de plásticos na produção de painéis de madeira. Em ambos os casos produziram-se, por compressão, painéis com boas propriedades físicas e mecânicas.

O objetivo deste trabalho foi avaliar as propriedades físicas e mecânicas de painéis produzidos pela mistura de partículas de madeira e de plástico (poliestireno e polietileno tereftalato), empregando adesivos de uréiaformaldeído e fenol-formaldeído e uma solução de poliestireno em tolueno como agentes de ligação.

\section{MATERIALEMÉTODOS}

\subsection{Material}

A madeira empregada na produção dos painéis de partículas foi obtida em um povoamento de Pinus elliottii, com 33 anos de idade, existentes em área do campus da Universidade Federal de Viçosa, Viçosa-MG. As resinas termoplásticas de poliestireno (PS) e polietileno tereftalato (PET), foram obtidas de um depósito de materiais recicláveis localizado na mesma instituição. O poliestireno também foi obtido por coleta semi-seletiva de plástico 
pós-consumido, descartado de algumas lanchonetes, localizadas na cidade de Viçosa, como uma mistura de polímeros estirênicos na forma de copos, pratos e envases. O PET foi coletado unicamente na forma de envases

\subsection{Preparação das Partículas}

Foram previamente selecionadas e colhidas nove árvores do gênero Pinus. Cada uma das árvores foi transformada em toretes de $0,80 \mathrm{~cm}$, sendo estes transformados em tábuas com $2,5 \mathrm{~cm}$ de espessura.

As tábuas obtidas foram transformadas, por cortes perpendiculares à grã da madeira, em blocos de $2,5 \mathrm{~cm}$ de espessura, $7 \mathrm{~cm}$ de comprimento e largura correspondente à largura da tábua. Após ficarem mergulhados em água, por cerca de cinco dias, os blocos foram transformados em flocos, com espessura média de $0,055 \mathrm{~mm}$, em um moinho de facas. Em seguida, os flocos foram secos ao ar durante sete dias e depois reduzidos a partículas em moinho de martelos, equipado com peneira de malha de $3 \times 17 \mathrm{~mm}$. As partículas foram selecionadas em peneira de malha com abertura de $1,0 \times 1,0 \mathrm{~mm}$, tendo sido aproveitadas as que não passaram pela respectiva malha.

Os plásticos de poliestireno e de PET, depois de lavados e isentos de impurezas, foram transformados, ainda úmidos, em partículas, utilizando moinho de martelos equipado com peneira com orifícios de $4 \mathrm{~mm}$ de diâmetro. As partículas obtidas foram novamente moídas no mesmo moinho, equipado, então, com peneira com abertura de 1,5 x $19 \mathrm{~mm}$, para redução de seu tamanho. As partículas de PET foram classificadas em peneira de malha com abertura de 1,0 x 1,0 mm, tendo sido aproveitadas as que não passaram pela respectiva malha. As partículas de poliestireno, por apresentarem a geometria desejada, não passaram por esta etapa de seleção. Quando previsto, o poliestireno foi dissolvido em tolueno, preparando-se uma solução com $20 \%$ do plástico.

As densidades da madeira, do poliestireno e do PET foram, respectivamente, iguais a 0,40, $0,85 \mathrm{e} 1,13 \mathrm{~g} / \mathrm{cm}^{3}$.

\subsection{Preparação dos Painéis}

Todos os painéis foram produzidos de forma a se ter densidade final igual a $0,60 \mathrm{~g} / \mathrm{cm}^{3}$ e espessura igual a $10 \mathrm{~mm}$, tendo as frações de madeira e plástico sido calculadas em função destes parâmetros. Para o cálculo da massa de madeira considerou-se um teor de umidade de $3 \%$, enquanto para os plásticos consideraram-se as partículas isentas de umidade.

Foram utilizados adesivos à base de uréia-formaldeído, Cascamite PL117, e à base de fenol-formaldeído, Cascophen HL - 2080, contendo 65 e 50,5\% de sólidos resinosos, respectivamente. $\mathrm{O}$ catalisador endurecedor para o adesivo uréico foi o sulfato de amônia $\left(\mathrm{NH}_{4}\right) \mathrm{SO}_{4}$, em solução de $20 \%$, na proporção de $1,5 \%$ em relação ao teor de sólidos da quantidade de adesivo utilizada. A quantidade de adesivos aplicados nos painéis foi de 4 e $6 \%$ de sólidos resinosos, com base na massa da mistura empregada. As partículas de madeira e de plástico foram pesadas e colocadas no interior de um misturador tipo tambor rotatório, com 1,2 m de diâmetro e 0,5 m de largura, que girava a uma velocidade de 26 rotações por minuto. $\mathrm{O}$ adesivo e a solução de poliestireno em tolueno foram aplicados por meio de bico injetor, acionado por compressor de ar, durante um tempo médio de aplicação de 5 minutos. $\mathrm{O}$ método de aplicação consistiu em adicionar primeiro o adesivo e, quando previsto, aplicou-se a solução de poliestireno em tolueno.

A mistura de partículas de madeira e plástico, depois de aspergida com os aditivos, foi pesada, para cada repetição, e levada para a seção formadora do colchão. $\mathrm{O}$ colchão foi formado manualmente, depositando-se, de uma só vez, a mistura de partículas sobre uma chapa de alumínio de 3,5 mm de espessura, colocada sobre uma caixa de madeira sem fundo, com dimensões internas de aproximadamente $400 \times 400 \times 160 \mathrm{~mm}$, as quais foram então cuidadosamente espalhadas de forma aleatória.

O colchão foi prensado em prensa com aquecimento elétrico, ajuste independente de temperatura nos pratos e controle de pressão aplicada. O ciclo de prensagem, conforme mostra a Figura 1, obedeceu à seguinte condição: temperatura, $185{ }^{\circ} \mathrm{C}$; pressão, $32 \mathrm{kgf} / \mathrm{cm}^{2}$; tempo, 5 minutos. $\mathrm{O}$ ciclo foi composto de dois patamares de pressão, ambos de $32 \mathrm{kgf} / \mathrm{cm}^{2}$, necessários para que a chapa atingisse a espessura final desejada. Para obter esses patamares, o fechamento dos pratos da prensa foi executado em dois estágios; no primeiro foram gastos 10 segundos para atingir $32 \mathrm{kgf} / \mathrm{cm}^{2}$, permanecendo nesta pressão por 60 segundos, quando a pressão decresceu para valores próximos a $12 \mathrm{kgf} / \mathrm{cm}^{2}$, em 60 segundos; neste ponto aplicou-se pressão durante 5 segundos, atingindo o segundo patamar de $32 \mathrm{kgf} / \mathrm{cm}^{2}$, permanecendo neste estágio por 120 segundos. Passado este tempo a pressão no monômero decresceu lentamente durante 60 segundos, para valores próximos de zero, quando a prensa foi aberta, totalizando 300 segundos.

R. Árvore, Viçosa-MG, v.28, n.2, p.257-266, 2004 


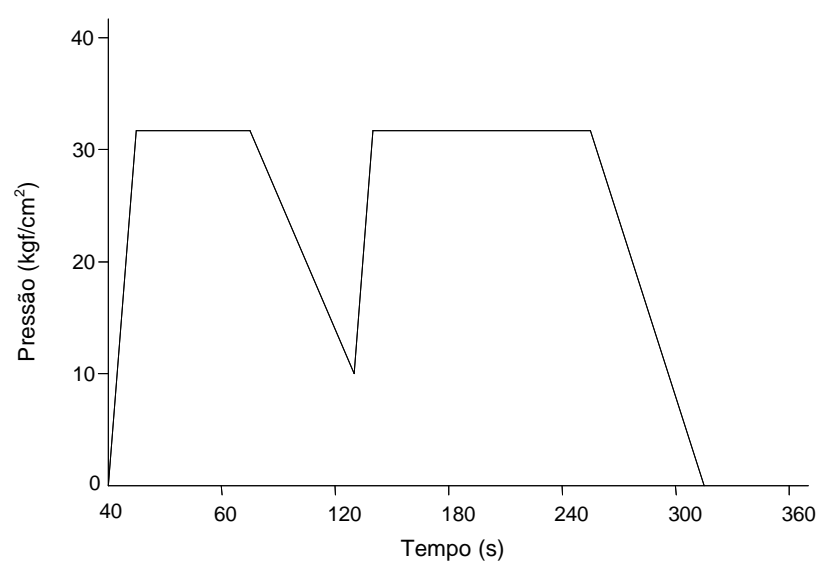

Figura 1 - Ciclo de prensagem aplicado na produção de painéis de madeira/plástico.

Figure 1 - Press diagram for production of wood/plastic boards.
O tempo de prensagem utilizado foi aquele usado em painéis comerciais de madeira aglomerada, tendo sido calculado segundo recomendação da Alba Química, que indica que se considere de 7 a 8 segundos por milímetro de chapa, quando estes produtos são elaborados em temperaturas que variam entre 180 e $190{ }^{\circ} \mathrm{C}$.

Os painéis de aproximadamente $400 \times 400$ x $10 \mathrm{~mm}$, em camada única, foram mantidos no interior de caixas à temperatura ambiente, por cerca de 10 dias, e, em seguida, tiveram suas bordas aparadas para $380 \times 380 \mathrm{~mm}$, e suas superfícies lixadas. De cada chapa foram retirados dois corpos-de-prova, para execução dos ensaios de flexão estática (módulo de ruptura - MOR e módulo de elasticidade - MOE); absorção de água e inchamento em espessura; e seis corpos-de-prova, para tração perpendicular à superfície da chapa, segundo o modelo de corte representado na Figura 2. Os corpos-de-prova utilizados para

38,00

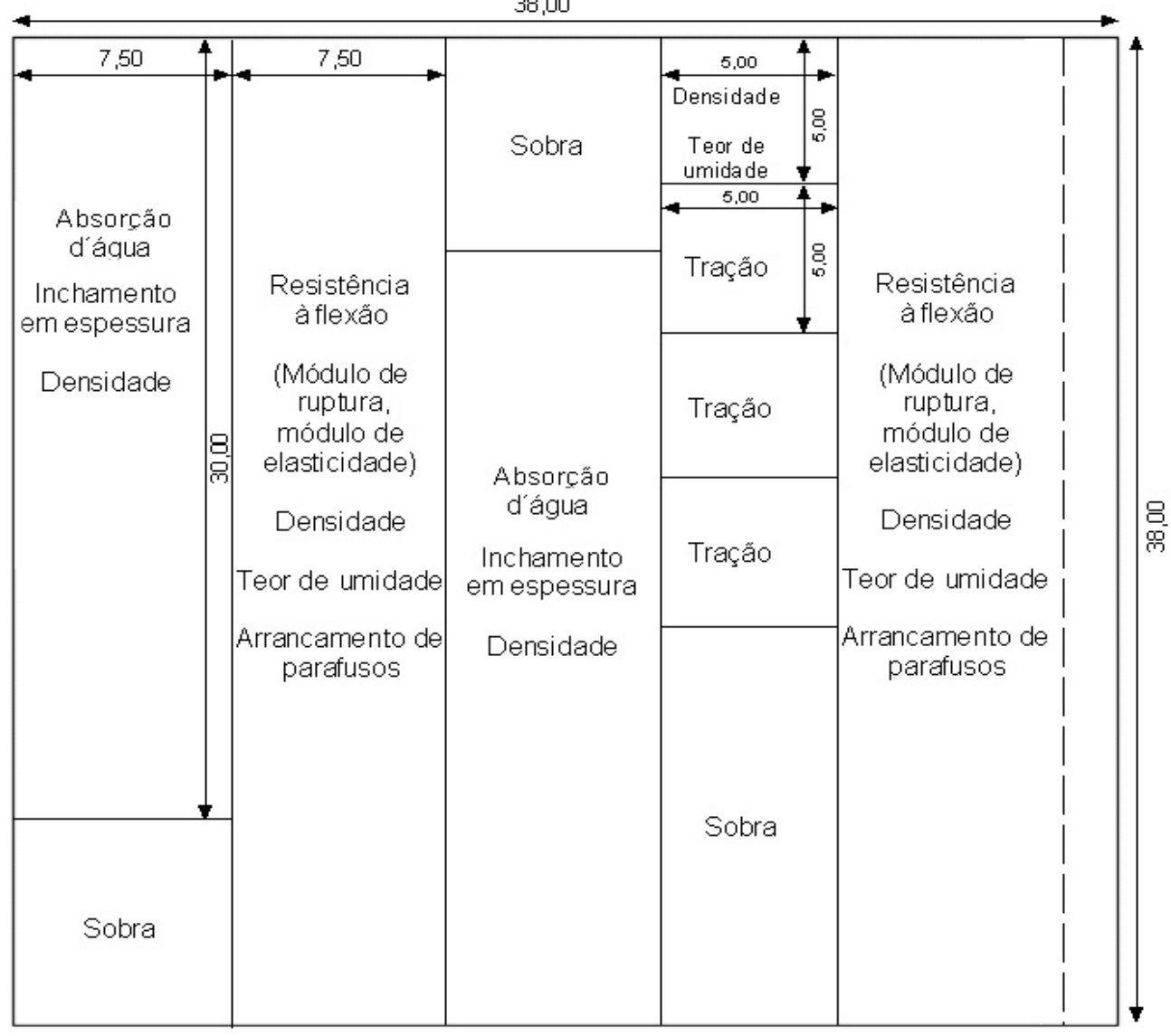

Figura 2 - Diagrama de corte das amostras para teste.

Figure 2 - Cutting diagram for test specimens.

R. Árvore, Viçosa-MG, v.28, n.2, p.257-266, 2004 
determinar a densidade e o teor de umidade foram retirados de uma das extremidades dos corpos-de-prova, utilizados para determinar a resistência à flexão estática, perfazendo quatro corpos-de-prova por chapa. A outra extremidade foi aproveitada para o teste de arrancamento de parafuso perpendicular à superfície da chapa, perfazendo dois corpos-de-prova por chapa. As amostras foram climatizadas em ambiente de umidade relativa do ar de $65 \%$ e temperatura de $23{ }^{\circ} \mathrm{C}$, até atingirem a umidade de equilíbrio do ambiente. $\mathrm{O}$ teor de umidade foi determinado em base seca, pelo processo de secagem em estufa com ventilação de ar forçada a $103 \pm 2{ }^{\circ} \mathrm{C}$, até peso constante. Os corpos-de-prova foram testados de acordo com a norma americana ASTMD 1037-1991, em uma máquina universal de testes.

\subsection{Delineamento Experimental}

O experimento foi instalado seguindo um delineamento inteiramente casualizado, com 22 tratamentos e duas repetições, conforme mostra o Quadro 1, totalizando 44 painéis. Os resultados dos testes das variáveis foram submetidos à análise de variância (ANOVA), para comparação entre os tratamentos, a 1 e 5\% de probabilidade.

Os tratamentos, para cada tipo de adesivo, foram comparados entre si por meio do teste de Scott-Knott, a $5 \%$ de probabilidade. A comparação entre adesivos foi feita por meio do teste $\mathrm{t}$ de Student, a $5 \%$ de probabilidade.

\section{RESULTADOS E DISCUSSÃO}

Conforme pode ser observado no Quadro 2, tanto os painéis produzidos apenas com partículas de madeira quanto aqueles produzidos com partículas de PS ou de PET/PS não foram afetados pelo aumento no teor de adesivo, embora se perceba uma tendência de aumento do módulo de ruptura para um nível mais elevado de adesivo, resultado coerente com aqueles encontrados na literatura (Kolmann et al., 1975; Moslemi 1974; Maloney,1993). Para os painéis produzidos com adesivo à base de uréia-formaldeído e contendo partículas de PS ou PET/PS, o aumento no teor de adesivo não promoveu diferença significativa na resistência do módulo de ruptura. O mesmo efeito foi observado nos painéis produzidos com adesivo fenólico. Para os painéis em que se adicionou a solução de PS não houve diferença significativa entre os tratamentos. Os painéis com maior módulo de ruptura foram aqueles produzidas com $50 \%$ de poliestireno, solução de poliestireno em tolueno, bem como $25 \%$ de poliestireno, sem solução de poliestireno em tolueno, com 4 ou $6 \%$ de adesivo. Para os painéis contendo PET/OS, os valores médios mais elevados foram observados nos painéis com 5/20 de PET/PS, solução de tolueno e $6 \%$ de adesivo.

O MOR dos painéis em que se utilizou apenas a solução de PS em solução como adesivo foi menor do que o daqueles fabricados com a mesma composição e que receberam o adesivo fenólico.

De modo geral, todas os painéis que continham em sua composição partículas de madeira e poliestireno apresentaram valores de módulo de ruptura superiores aos dos painéis fabricados apenas com madeira.

Quadro 1 - Composições experimentais utilizadas na produção dos painéis

Table 1 -Experimental compositions for board production

\begin{tabular}{|c|c|}
\hline Trat. & Composição \\
\hline $\mathrm{T}_{1}$ & $0 \%$ PS / $100 \%$ madeira / $4 \%$ adesivo \\
\hline $\mathrm{T}_{2}$ & $0 \%$ PS / $100 \%$ madeira / $6 \%$ adesivo \\
\hline $\mathrm{T}_{3}$ & $\begin{array}{l}25 \% \text { PS / } 75 \% \text { madeira / } 0 \% \text { adesivo / } 6 \% \text { solução de } \\
\text { polistireno em tolueno }\end{array}$ \\
\hline $\mathrm{T}_{4}$ & $\begin{array}{l}25 \% \text { PS / } 75 \% \text { madeira / } 4 \% \text { adesivo / } 4 \% \text { solução de } \\
\text { polistireno em tolueno }\end{array}$ \\
\hline $\mathrm{T}_{5}$ & $\begin{array}{l}25 \% \text { PS / } 75 \% \text { madeira / } 6 \% \text { adesivo / } 4 \% \text { solução de } \\
\text { polistireno em tolueno }\end{array}$ \\
\hline $\mathrm{T}_{6}$ & $\begin{array}{l}50 \% \text { PS / } 50 \% \text { madeira / } 0 \% \text { adesivo / } 6 \% \text { solução de } \\
\text { polistireno em tolueno }\end{array}$ \\
\hline $\mathrm{T}_{7}$ & $\begin{array}{l}50 \% \text { PS / } 50 \% \text { madeira / } 4 \% \text { adesivo / } 4 \% \text { solução de } \\
\text { polistireno em tolueno }\end{array}$ \\
\hline $\mathrm{T}_{8}$ & $\begin{array}{l}50 \% \text { PS / } 50 \% \text { madeira / } 6 \% \text { adesivo / } 4 \% \text { solução de } \\
\text { polistireno em tolueno }\end{array}$ \\
\hline $\mathrm{T}_{9}$ & $25 \%$ PS / $75 \%$ madeira / $4 \%$ adesivo \\
\hline $\mathrm{T}_{10}$ & $25 \%$ PS / $75 \%$ madeira / $6 \%$ adesivo \\
\hline $\mathrm{T}_{11}$ & $50 \%$ PS / $50 \%$ madeira / $4 \%$ adesivo \\
\hline $\mathrm{T}_{12}$ & $50 \%$ PS / $50 \%$ de madeira / $6 \%$ adesivo \\
\hline $\mathrm{T}_{13}$ & $\begin{array}{l}\text { 5/20 (PET/PS) / 75\% madeira / } 0 \% \text { adesivo / } 6 \% \text { solução de } \\
\text { polistireno em tolueno }\end{array}$ \\
\hline $\mathrm{T}_{14}$ & $\begin{array}{l}5 / 20 \text { (PET/PS) / 75\% madeira / 4\% adesivo / } 4 \% \text { solução de } \\
\text { polistireno em tolueno }\end{array}$ \\
\hline $\mathrm{T}_{15}$ & $\begin{array}{l}5 / 20(\mathrm{PET} / \mathrm{PS}) / 75 \% \text { madeira / } 6 \% \text { adesivo / } 4 \% \text { solução de } \\
\text { polistireno em tolueno }\end{array}$ \\
\hline $\mathrm{T}_{16}$ & $\begin{array}{l}10 / 40 \text { (PET/PS) / } 50 \% \text { madeira / } 0 \% \text { adesivo / } 6 \% \text { solução } \\
\text { de polistireno em tolueno }\end{array}$ \\
\hline $\mathrm{T}_{17}$ & $\begin{array}{l}\text { 10/40 (PET/PS) / } 50 \% \text { madeira / } 4 \% \text { adesivo / } 4 \% \text { solução } \\
\text { de polistireno em tolueno }\end{array}$ \\
\hline $\mathrm{T}_{18}$ & $\begin{array}{l}\text { 10/40 (PET/PS) / 50\% madeira / } 6 \% \text { adesivo / } 4 \% \text { solução } \\
\text { de polistireno em tolueno }\end{array}$ \\
\hline $\mathrm{T}_{19}$ & $5 / 20$ (PET/PS) / 75\% madeira / $4 \%$ adesivo \\
\hline $\mathrm{T}_{20}$ & $5 / 20$ (PET/PS) / 75\% madeira / $6 \%$ adesivo \\
\hline $\mathrm{T}_{21}$ & 10/40 (PET/PS) / $50 \%$ madeira / 4\% adesivo \\
\hline $\mathrm{T}_{22}$ & $10 / 40$ (PET/PS) / 50\% madeira / $6 \%$ adesivo \\
\hline
\end{tabular}

R. Árvore, Viçosa-MG, v.28, n.2, p.257-266, 2004 
Observou-se ainda que apesar do baixo teor de adesivo empregado foi possível produzir painéis com MOR superior ao valor mínimo (0,50Mpa) exigido pela norma ANSI/ A 208.1-1993.

Analisando o Quadro 2 observa-se ainda que os diversos tratamentos não afetaram significativamente o valor do módulo de elasticidade (MOE) nos painéis produzidos com adesivo de uréia-formaldeído. Os maiores valores de MOE foram observados, quase na totalidade, nos painéis produzidos com plástico, dentro dos níveis de adesivos considerados. Mesmo não havendo diferença significativa, observa-se a tendência de MOE mais elevado para os produtos fabricados com 25, 50 de PS e $5 / 20 \%$ de PET/PS, solução de poliestireno em tolueno e $6 \%$ de adesivo. Contudo, efeito significativo foi observado nos painéis produzidos com adesivo fenólico.

Tanto para os painéis produzidos apenas com partículas de madeira quanto para aqueles produzidos com partículas de PS ou PET/PS, o aumento no teor de adesivo resulta em aumento do módulo de elasticidade, independentemente do uso ou não da solução de poliestireno em tolueno. Assim, a intensidade do efeito no MOE foi afetada pela composição dos painéis.

De modo geral, todos os painéis em que se aplicou apenas a solução de poliestireno em tolueno como adesivo apresentaram valores médios de MOE inferiores aos dos painéis produzidos com madeira ou algum tipo de plástico, exceção daqueles produzidos com 5/20\% de $\mathrm{PET} / \mathrm{PS}$.

Praticamente, todos os painéis elaborados com partículas de madeira e poliestireno apresentaram valores médios de módulos de elasticidade superiores aos dos painéis produzidas com PET/PS.

Conforme pode ser observado no Quadro 3, a resistência à tração perpendicular à superfície de todos os painéis foi superior ao valor mínimo exigido pela norma

Quadro 2 - Resultados médios do módulo de ruptura (MPa) e módulo de elasticidade (Gpa) Table 2 - Rupture $(M p a)$ and elasticity $(G P a)$ model mean results

\begin{tabular}{|c|c|c|c|c|c|c|c|c|}
\hline \multirow{2}{*}{$\begin{array}{l}\text { Tipo de } \\
\text { Plástico }\end{array}$} & \multirow{2}{*}{$\begin{array}{l}\text { Trata- } \\
\text { mento }\end{array}$} & \multirow{2}{*}{$\begin{array}{l}\text { Teor de } \\
\text { Plástico }\end{array}$} & \multirow{2}{*}{$\begin{array}{l}\text { Teor de } \\
\text { Adesivo }\end{array}$} & \multirow{2}{*}{$\begin{array}{c}\text { Teor da Solução de } \\
\text { Poliestireno em } \\
\text { Tolueno }\end{array}$} & \multicolumn{2}{|c|}{ Módulo de Ruptura } & \multicolumn{2}{|c|}{ Módulo de Elasticidade } \\
\hline & & & & & Uréia & Fenol & Uréia & Fenol \\
\hline \multirow{10}{*}{ PS } & 1 & 0 & 4 & 0 & $11,21 \mathrm{Aa}$ & 8,69 Aa & 2,44 Aa & $1,85 \mathrm{Ba}$ \\
\hline & 2 & 0 & 6 & 0 & $15,81 \mathrm{Aa}$ & $13,14 \mathrm{Aa}$ & $2,97 \mathrm{Aa}$ & $2,30 \mathrm{Aa}$ \\
\hline & 4 & 25 & 4 & 4 & $12,61 \mathrm{Aa}$ & 9,95 Aa & $2,60 \mathrm{Aa}$ & $2,32 \mathrm{Ba}$ \\
\hline & 5 & 25 & 6 & 4 & $15,86 \mathrm{Aa}$ & $13,06 \mathrm{Ab}$ & $3,05 \mathrm{Aa}$ & $2,85 \mathrm{Aa}$ \\
\hline & 7 & 50 & 4 & 4 & $14,34 \mathrm{Aa}$ & $14,22 \mathrm{Aa}$ & $2,68 \mathrm{Aa}$ & $2,10 \mathrm{Aa}$ \\
\hline & 8 & 50 & 6 & 4 & $14,76 \mathrm{Aa}$ & $16,00 \mathrm{Aa}$ & $3,03 \mathrm{Aa}$ & $2,84 \mathrm{Aa}$ \\
\hline & 9 & 25 & 4 & 0 & $10,04 \mathrm{Aa}$ & $11,67 \mathrm{Aa}$ & $2,04 \mathrm{Aa}$ & $2,51 \mathrm{Aa}$ \\
\hline & 10 & 25 & 6 & 0 & $14,01 \mathrm{Aa}$ & $16,88 \mathrm{Aa}$ & $2,76 \mathrm{Aa}$ & 2,63 Aa \\
\hline & 11 & 50 & 4 & 0 & $13,20 \mathrm{Aa}$ & 9,11 Aa & $2,88 \mathrm{Aa}$ & $2,00 \mathrm{Aa}$ \\
\hline & 12 & 50 & 6 & 0 & $15,87 \mathrm{Aa}$ & $12,12 \mathrm{Aa}$ & $2,89 \mathrm{Aa}$ & $2,47 \mathrm{Ba}$ \\
\hline \multirow{8}{*}{ PET/PS } & 14 & $5 / 20$ & 4 & 4 & $13,79 \mathrm{Aa}$ & $8,41 \mathrm{Ab}$ & $2,61 \mathrm{Aa}$ & $1,76 \mathrm{Aa}$ \\
\hline & 15 & $5 / 20$ & 6 & 4 & $14,95 \mathrm{Aa}$ & $14,07 \mathrm{Aa}$ & $3,03 \mathrm{Aa}$ & $2,14 \mathrm{Aa}$ \\
\hline & 17 & $10 / 40$ & 4 & 4 & $11,17 \mathrm{Aa}$ & $11,67 \mathrm{Aa}$ & $2,19 \mathrm{Aa}$ & $2,02 \mathrm{Ba}$ \\
\hline & 18 & $10 / 40$ & 6 & 4 & $12,10 \mathrm{Aa}$ & $10,16 \mathrm{Aa}$ & $2,45 \mathrm{Aa}$ & $2,12 \mathrm{Ba}$ \\
\hline & 19 & $5 / 20$ & 4 & 0 & $10,90 \mathrm{Aa}$ & 10,13 Aa & $2,23 \mathrm{Aa}$ & $1,78 \mathrm{Bb}$ \\
\hline & 20 & $5 / 20$ & 6 & 0 & $11,78 \mathrm{Aa}$ & $10,60 \mathrm{Aa}$ & $2,45 \mathrm{Aa}$ & $2,11 \mathrm{Ba}$ \\
\hline & 21 & $10 / 40$ & 4 & 0 & $10,46 \mathrm{Aa}$ & $10,87 \mathrm{Aa}$ & $1,96 \mathrm{Aa}$ & $2,13 \mathrm{Ba}$ \\
\hline & 22 & $10 / 40$ & 6 & 0 & $11,60 \mathrm{Aa}$ & 9,94 Aa & $2,21 \mathrm{Aa}$ & $2,24 \mathrm{Ba}$ \\
\hline \multicolumn{9}{|c|}{ Sem Adesivos } \\
\hline \multirow{2}{*}{ PS } & 3 & 25 & 0 & 6 &. & $6,88 \mathrm{~A}$ & & $1,41 \mathrm{~B}$ \\
\hline & 13 & $5 / 20$ & 0 & 6 & . & $6,55 \mathrm{~A}$ & & $2,86 \mathrm{~B}$ \\
\hline \multirow{2}{*}{ PET/PS } & 6 & 50 & 0 & 6 & $\therefore$ & $11,60 \mathrm{~A}$ & & $1,61 \mathrm{~A}$ \\
\hline & 16 & $10 / 40$ & 0 & 6 & . & $7,75 \mathrm{~A}$ & & $1,49 \mathrm{~B}$ \\
\hline
\end{tabular}

Para cada adesivo, letras maiúsculas comparam o efeito dos tratamentos pelo teste de Scott-Knot, a 5\% de probabilidade. Para cada tratamento, letras minúsculas comparam o efeito do adesivo pelo teste t de Student, a $5 \%$ de probabilidade. 
ANSI / A 208.1-1993 (0,15 MPa), o que foi provavelmente ocasionado pelo efeito da solução de poliestireno, associada aos adesivos empregados na fabricação dos painéis. Os painéis com maior coesão interna foram aqueles produzidos com solução de poliestireno em tolueno e que continham em sua composição $25 \%$ de poliestireno e $6 \%$ de adesivo, quando comparados ao valor médio determinado nos painéis-testemunha com o mesmo nível de adesivo. Embora, de modo geral, não tenha sido detectada, pelo teste de Scott-Knott, diferença estatística entre os valores médios observados nos painéis com $6 \%$ de adesivo e solução de poliestireno em tolueno, percebese pelos resultados apresentados que estes valores superaram, numericamente, aqueles observados nos painéis sem plástico.

Dentro de um mesmo tipo de plástico, a utilização da solução de poliestireno em tolueno, associada ao nível de adesivo, favoreceu a ligação interna dos painéis produzidos, independentemente do tipo de adesivo utilizado.
A ligação interna dos painéis em que se utilizou apenas a solução de poliestireno como adesivo foi menor que nos fabricados com a mesma composição e que receberam o adesivo fenólico. Entretanto, dentro desta mesma classe os painéis elaborados com $50 \%$ de poliestireno apresentaram valor médio de coesão mais elevado.

De modo geral, nos painéis em que houve efeito significativo do tipo de adesivo, aqueles produzidos com adesivo de uréia foram os mais resistentes.

No ensaio de arrancamento de parafuso perpendicular à superfície da chapa, a norma ANSI /A 208.1-1993 exige, no mínimo, $550 \mathrm{~N}$. Conforme pode ser observado no Quadro 3, todos os painéis produzidos superaram este valor, inclusive aqueles produzidos sem adesivo, não se observando, de modo geral, diferença significativa entre os tratamentos, particularmente naqueles em que os painéis foram confeccionados com adesivos fenólicos . Os painéis com 25 e $50 \%$ de PS e 5/20\% e 10/40 de PET / PS,

Quadro 3 - Resultados médios da resistência à tração perpendicular e arrancamento de parafuso (MPa) Table 3 - Internal bond and screw withdrawal mean results (MPa)

\begin{tabular}{|c|c|c|c|c|c|c|c|c|}
\hline \multirow{2}{*}{$\begin{array}{l}\text { Tipo de } \\
\text { Plástico }\end{array}$} & \multirow{2}{*}{$\begin{array}{l}\text { Trata- } \\
\text { mento }\end{array}$} & \multirow{2}{*}{$\begin{array}{l}\text { Teor de } \\
\text { Plástico }\end{array}$} & \multirow{2}{*}{$\begin{array}{l}\text { Teor de } \\
\text { Adesivo }\end{array}$} & \multirow{2}{*}{$\begin{array}{c}\text { Teor da Solução de } \\
\text { Poliestireno em } \\
\text { Tolueno }\end{array}$} & \multicolumn{2}{|c|}{ Tração Perpendicular } & \multicolumn{2}{|c|}{ Arrancamento de Parafuso } \\
\hline & & & & & Uréia & Fenol & Uréia & Fenol \\
\hline \multirow{10}{*}{ PS } & 1 & 0 & 4 & 0 & $0,30 \mathrm{Ea}$ & $0,33 \mathrm{Ea}$ & $1483 \mathrm{Ba}$ & $1313 \mathrm{Aa}$ \\
\hline & 2 & 0 & 6 & 0 & $0,57 \mathrm{Ca}$ & $0,52 \mathrm{Da}$ & $1817 \mathrm{Aa}$ & $1697 \mathrm{Aa}$ \\
\hline & 4 & 25 & 4 & 4 & $0,37 \mathrm{Da}$ & $0,41 \mathrm{Ea}$ & $1696 \mathrm{Aa}$ & $1558 \mathrm{Aa}$ \\
\hline & 5 & 25 & 6 & 4 & $0,66 \mathrm{Ab}$ & $0,75 \mathrm{Ba}$ & $1726 \mathrm{Aa}$ & $2000 \mathrm{Aa}$ \\
\hline & 7 & 50 & 4 & 4 & $0,48 \mathrm{Ba}$ & $0,44 \mathrm{Ea}$ & $1993 \mathrm{Aa}$ & $1641 \mathrm{Aa}$ \\
\hline & 8 & 50 & 6 & 4 & $0,52 \mathrm{Ab}$ & $0,60 \mathrm{Da}$ & $2139 \mathrm{Aa}$ & $1969 \mathrm{Aa}$ \\
\hline & 9 & 25 & 4 & 0 & $0,22 \mathrm{~Eb}$ & $0,33 \mathrm{Fa}$ & $1325 \mathrm{Ba}$ & $1525 \mathrm{Aa}$ \\
\hline & 10 & 25 & 6 & 0 & $0,45 \mathrm{Cb}$ & $0,55 \mathrm{Da}$ & $1714 \mathrm{Aa}$ & $1641 \mathrm{Aa}$ \\
\hline & 11 & 50 & 4 & 0 & $0,40 \mathrm{Ea}$ & $0,31 \mathrm{Fb}$ & $1373 \mathrm{Ba}$ & $1288 \mathrm{Aa}$ \\
\hline & 12 & 50 & 6 & 0 & $0,44 \mathrm{Ca}$ & $0,41 \mathrm{Ea}$ & $1702 \mathrm{Aa}$ & $1459 \mathrm{Aa}$ \\
\hline \multirow{8}{*}{ PET/PS } & 14 & $5 / 20$ & 4 & 4 & $0,51 \mathrm{Ea}$ & $0,38 \mathrm{~Eb}$ & $1373 \mathrm{Aa}$ & $1428 \mathrm{Aa}$ \\
\hline & 15 & $5 / 20$ & 6 & 4 & 0,67 Aa & 0,61 Aa & $2121 \mathrm{Aa}$ & $2103 \mathrm{Aa}$ \\
\hline & 17 & $10 / 40$ & 4 & 4 & $0,31 \mathrm{Da}$ & $0,40 \mathrm{Da}$ & $1744 \mathrm{Aa}$ & $1598 \mathrm{Aa}$ \\
\hline & 18 & $10 / 40$ & 6 & 4 & $0,58 \mathrm{Ca}$ & $0,57 \mathrm{Ca}$ & $1933 \mathrm{Aa}$ & $1933 \mathrm{Aa}$ \\
\hline & 19 & $5 / 20$ & 4 & 0 & $0,34 \mathrm{Ea}$ & $0,29 \mathrm{Fa}$ & $1112 \mathrm{Ba}$ & $1519 \mathrm{Aa}$ \\
\hline & 20 & $5 / 20$ & 6 & 0 & $0,49 \mathrm{Cb}$ & $0,58 \mathrm{Da}$ & $1367 \mathrm{Ba}$ & $1726 \mathrm{Aa}$ \\
\hline & 21 & $10 / 40$ & 4 & 0 & $0,22 \mathrm{~Eb}$ & $0,35 \mathrm{Fa}$ & $1380 \mathrm{Ba}$ & $1349 \mathrm{Aa}$ \\
\hline & 22 & $10 / 40$ & 6 & 0 & $0,29 \mathrm{~Eb}$ & $0,43 \mathrm{Fa}$ & $1598 \mathrm{Ba}$ & $1313 \mathrm{Aa}$ \\
\hline \multicolumn{9}{|c|}{ Sem Adesivos } \\
\hline \multirow{2}{*}{ PS } & 3 & 25 & 0 & 6 & . & $0,12 \mathrm{G}$ & & $1446 \mathrm{~A}$ \\
\hline & 6 & 50 & 0 & 6 & . & $0,22 \mathrm{~F}$ & & $1629 \mathrm{~A}$ \\
\hline \multirow{2}{*}{$\mathrm{PET} / \mathrm{PS}$} & 13 & $5 / 20$ & 0 & 6 & $\therefore$ & $0,12 \mathrm{H}$ & & $869 \mathrm{~A}$ \\
\hline & 16 & $10 / 40$ & 0 & 6 & . & $0,17 \mathrm{H}$ & & $1449 \mathrm{~A}$ \\
\hline
\end{tabular}

Para cada adesivo, letras maiúsculas comparam o efeito dos tratamentos pelo teste de Scott-Knot, a 5\% de probabilidade. Para cada tratamento, letras minúsculas comparam o efeito do adesivo pelo teste $t$ de Student, a $5 \%$ de probabilidade. 
4 e $6 \%$ de adesivo e solução de tolueno mostraram valores superiores aos determinados nos painéis sem plástico. Os painéis que apresentaram valores médios mais elevados para o arrancamento de parafusos foram aqueles produzidos com solução de poliestireno em tolueno, independentemente da relação de mistura utilizada. Os painéis com $50 \%$ de poliestireno, 4 e $6 \%$ de adesivo e solução de tolueno mostraram valores superiores aos determinados nos painéis sem plástico. Para a relação PET/PS igual a 5/20\%, os valores encontrados, quando comparados aos dos painéis sem plástico, também se mostraram superiores dentro dos mesmos níveis de adesivo. Não foram observadas diferenças significativas ocasionadas pelo tipo de adesivo.

No ensaio de absorção de água, após 24 horas de imersão, conforme pode ser constatado no Quadro 4, todos os painéis que continham plástico apresentaram valores de absorção inferiores aos dos painéis sem plástico, sendo aqueles produzidos com $50 \%$ de poliestireno e solução de tolueno os que apresentaram os menores valores médios de absorção. Neste caso, bem como para as demais variáveis analisadas, pôde-se observar o efeito benéfico do tolueno, ao se comparar os tratamentos onde esta substância foi aplicada com os tratamentos similares sem tolueno.

Entre os painéis fabricados sem adesivo, aqueles que apresentaram menores valores médios de absorção de água foram produzidos com $50 \%$ de plástico. Tal fato ocorreu porque o plástico, de acordo com a literatura especializada, não absorve água.

O inchamento em espessura, após 24 horas de imersão em água, para os painéis que continham plástico, foi sempre inferior ao apresentado para painéis sem plástico. Os menores valores de inchamento foram observados nos painéis com maior conteúdo de plástico, independentemente de mistura de madeira/plástico empregada, estando os menores valores relacionados ao nível mais elevado de adesivo, $6 \%$.

Quadro 4 - Resultados médios de absorção de água e inchamento após 24 horas de imersão em água, em porcentagem Table 4 - Twenty four hour-water absorption and thickness swelling mean results \%

\begin{tabular}{|c|c|c|c|c|c|c|c|c|}
\hline \multirow{2}{*}{$\begin{array}{l}\text { Tipo de } \\
\text { Plástico }\end{array}$} & \multirow{2}{*}{$\begin{array}{l}\text { Trata- } \\
\text { mento }\end{array}$} & \multirow{2}{*}{$\begin{array}{l}\text { Teor de } \\
\text { Plástico }\end{array}$} & \multirow{2}{*}{$\begin{array}{l}\text { Teor de } \\
\text { Adesivo }\end{array}$} & \multirow{2}{*}{$\begin{array}{c}\text { Teor da Solução de } \\
\text { Poliestireno em } \\
\text { Tolueno }\end{array}$} & \multicolumn{2}{|c|}{ Absorção de Água } & \multicolumn{2}{|c|}{ Inchamento } \\
\hline & & & & & Uréia & Fenol & Uréia & Fenol \\
\hline \multirow{10}{*}{ PS } & 1 & 0 & 4 & 0 & $165,07 \mathrm{Aa}$ & $149,59 \mathrm{Ab}$ & $56,75 \mathrm{Aa}$ & $56,75 \mathrm{Aa}$ \\
\hline & 2 & (n) & 6 & 0 & $142,16 \mathrm{Ba}$ & $135,74 \mathrm{Ba}$ & $40,00 \mathrm{Ba}$ & $45,75 \mathrm{Ba}$ \\
\hline & 4 & 25 & 4 & 4 & $89,63 \mathrm{Ca}$ & $88,12 \mathrm{Ca}$ & $19,25 \mathrm{Ca}$ & $22,00 \mathrm{Ca}$ \\
\hline & 5 & 25 & 6 & 4 & $82,91 \mathrm{Ca}$ & $82,14 \mathrm{Ca}$ & $17,00 \mathrm{Da}$ & $19,25 \mathrm{Da}$ \\
\hline & 7 & 50 & 4 & 4 & $72,72 \mathrm{Da}$ & $55,33 \mathrm{Ca}$ & $11,75 \mathrm{Ca}$ & $14,00 \mathrm{Da}$ \\
\hline & 8 & 50 & 6 & 4 & $63,53 \mathrm{Da}$ & $52,54 \mathrm{Cb}$ & $8,50 \mathrm{Da}$ & $10,50 \mathrm{Da}$ \\
\hline & 9 & 25 & 4 & 0 & $84,22 \mathrm{Ca}$ & $87,37 \mathrm{Ca}$ & $23,00 \mathrm{Ca}$ & $26,40 \mathrm{Ca}$ \\
\hline & 10 & 25 & 6 & 0 & $81,24 \mathrm{Ca}$ & $84,53 \mathrm{Ca}$ & $20,40 \mathrm{Da}$ & $23,50 \mathrm{Ca}$ \\
\hline & 11 & 50 & 4 & 0 & $81,73 \mathrm{Ca}$ & $74,28 \mathrm{Ca}$ & $15,50 \mathrm{Da}$ & $18,60 \mathrm{Da}$ \\
\hline & 12 & 50 & 6 & 0 & $79,97 \mathrm{Ca}$ & $69,64 \mathrm{Cb}$ & $11,10 \mathrm{Da}$ & $13,40 \mathrm{Da}$ \\
\hline \multirow{8}{*}{ PET/PS } & 14 & $5 / 20$ & 4 & 4 & $81,79 \mathrm{Ca}$ & $95,66 \mathrm{Ca}$ & $23,80 \mathrm{Ca}$ & $26,95 \mathrm{Ca}$ \\
\hline & 15 & $5 / 20$ & 6 & 4 & $79,28 \mathrm{Db}$ & $80,50 \mathrm{Ca}$ & $21,40 \mathrm{Ca}$ & $24,00 \mathrm{Ca}$ \\
\hline & 17 & $10 / 40$ & 4 & 4 & $70,32 \mathrm{Ca}$ & $79,42 \mathrm{Ca}$ & $18,00 \mathrm{Da}$ & $21,00 \mathrm{Da}$ \\
\hline & 18 & $10 / 40$ & 6 & 4 & $68,80 \mathrm{Da}$ & $71,83 \mathrm{Ca}$ & $11,80 \mathrm{Da}$ & $15,40 \mathrm{Da}$ \\
\hline & 19 & $5 / 20$ & 4 & 0 & $89,98 \mathrm{Ca}$ & $92,27 \mathrm{Ca}$ & $28,80 \mathrm{Ca}$ & $30,00 \mathrm{Ca}$ \\
\hline & 20 & $5 / 20$ & 6 & 0 & $87,65 \mathrm{Ca}$ & $90,83 \mathrm{Ca}$ & $26,65 \mathrm{Ca}$ & $20,35 \mathrm{Cb}$ \\
\hline & 21 & $10 / 40$ & 4 & 0 & $81,09 \mathrm{Ca}$ & $89,26 \mathrm{Ca}$ & $20,60 \mathrm{Da}$ & $24,20 \mathrm{Da}$ \\
\hline & 22 & $10 / 40$ & 6 & 0 & $78,54 \mathrm{Ca}$ & $84,00 \mathrm{Ca}$ & $16,65 \mathrm{Da}$ & $18,95 \mathrm{Da}$ \\
\hline \multicolumn{9}{|c|}{ Sem Adesivos } \\
\hline \multirow{2}{*}{ PS } & 3 & 25 & 0 & 6 & . & $131,53 \mathrm{~B}$ & & $25,00 \mathrm{C}$ \\
\hline & 6 & 50 & 0 & 6 & . & $48,51 \mathrm{C}$ & & $4,25 \mathrm{D}$ \\
\hline \multirow{2}{*}{ PET/PS } & 13 & $5 / 20$ & 0 & 6 & & $93,21 \mathrm{~A}$ & & $30,50 \mathrm{~B}$ \\
\hline & 16 & $10 / 40$ & 0 & 6 & & $99,65 \mathrm{C}$ & & $6,00 \mathrm{C}$ \\
\hline
\end{tabular}

Para cada adesivo, letras maiúsculas comparam o efeito dos tratamentos pelo teste de Scott-Knot, a 5\% de probabilidade. Para cada tratamento, letras minúsculas comparam o efeito do adesivo pelo teste t de Student, a 5\% de probabilidade. 
Para a maioria dos painéis não se observou efeito significativo do tipo de adesivo. Para os painéis em que este efeito foi observado, aqueles produzidos com adesivo à base de fenol tiveram maior inchamento. Isto não era esperado, uma vez que o adesivo à base de uréiaformaldeído não é resistente à umidade.

Embora as normas para comercialização de painéis de partículas não estabeleçam limites para absorção de água ou inchamento em espessura, na prática observa-se uma faixa bastante ampla de valores para estas propriedades. Conforme a tabela de propriedades físicas e mecânicas editadas pelo FOREST PRODUCTS LABORATORY (1987), os painéis comerciais de partículas de madeira têm apresentado, para o teste de absorção de água e inchamento em espessura, após 24 horas de imersão, valores entre 5 e $50 \%$ e 10 e $50 \%$, respectivamente. Desta forma, observa-se pelos resultados obtidos que, de modo geral, os painéis produzidos com plástico apresentaram um comportamento semelhante ao verificado nos painéis de partículas comercializados. Porém devese ressaltar que não foi utilizada parafina em emulsão, o que, provavelmente, reduziria a variação dimensional dos painéis.

Todas os painéis produzidos sem adesivo apresentaram, de modo geral, valores médios inferiores aos dos painéis com adesivo, para todas as propriedades avaliadas.

\section{CONCLUSÕES}

Todas as propriedades mecânicas dos painéis à base de madeira/plástico estudadas neste trabalho foram superiores aos mínimos exigidos pela norma ANSI/A 208.1-1993, para painéis de partículas de baixa densidade. Tanto para os painéis produzidos apenas com partículas de madeira quanto para aqueles produzidos com partículas de PS ou de PET/OS, o aumento no teor de adesivo resultou em painéis mais resistentes, o que está de acordo com a literatura (Moslemi, 1974; Kolmann et al., 1975). Para os painéis produzidos com adesivo à base de uréiaformaldeído contendo partículas de PS e solução de poliestireno, percebe-se a tendência de valores médios mais elevados para o MOR e MOE, quando comparados aos produtos elaborados com adesivos fenólicos. Para a tração perpendicular, independentemente da composição dos painéis e do adesivo utilizado, todos os incrementos foram significativos. Para o arrancamento de parafusos, os painéis produzidos com adesivo de uréia sem solução de tolueno foram os que apresentaram os menores valores de resistência. Para o adesivo fenólico, os painéis não sofreram o efeito dos tratamentos e do tipo de adesivo.

De modo geral, os painéis produzidos com 25 e $50 \%$ de poliestireno, solução de poliestireno em tolueno e 4 e $6 \%$ de adesivo mostraram, em quase totalidade, valores de resistência superiores aos demais, dentro de um mesmo nível de adesivo, superando também, em intensidade, os valores de resistência mecânica determinadas nos painéis sem plástico. A adição da mistura PET/PS sem a adição concomitante de PS em solução foi prejudicial à resistência dos painéis.

Quanto à absorção de água após 24 horas de imersão, todos os painéis excederam o valor máximo normalmente observado em painéis comerciais. O inchamento em espessura, no entanto, foi semelhante àqueles normalmente obtidos em painéis disponíveis no mercado.

A utilização da solução de poliestireno em tolueno foi importante para se obter produtos de boa qualidade. Por ter ação de solvência sobre o poliestireno, é provável que o tolueno tenha promovido nas superfícies deste plástico sua dissolução parcial, levando à melhor adesão entre as partículas do poliestireno e da madeira. É possível que as resinas termoendurecíveis utilizadas tenham também atuado como agente de ligação entre as superfícies hidrofóbicas do plástico e das hidrofílicas da madeira.

\section{REFERÊNCIAS BIBLIOGRÁFICAS}

AMERICAN NATIONAL STANDARD - ANSI. Matformed wood particleboard: specification ANSI A 208.1.1993. Gaithersburg: National Particleboards Association, $1993.9 \mathrm{p}$.

AMERICAN SOCIETY FOR TESTING AND

MATERIALS - ASTM. Standard test methods for evaluating properties of wood-base fiber and particle panels: ASTM D 1037-91. Philadelphia: ADTM, v. 04.09, 1991. (Annual Book of ASTM Standards).

ANUÁRIO BRASILEIRO DO PLÁSTICO. Plástico moderno. São Paulo: 2000.

BANCO NACIONAL DE DESENVOLVIMENTO ECONÔMICO E SOCIAL - BNDES. Produtos florestais. Área de operações industriais - gerência setorial 1, 2000.

BREGNER, K. I.; SCHNEIDER, M. H.; JONES, R. T. The influence of moisture content an the flexural strength of styrene-polymerized wood. Forest Products Journal, v. 38, n. 4 , p. $55-58,1988$.

R. Árvore, Viçosa-MG, v.28, n.2, p.257-266, 2004 
ENGLISH, B. et al. Waste-wood-Derived fillers for plastics. Gen. Tech. Rep. FPL-GTR-91.Madison, WI:U.S.

Department of Agriculture, Forest Service, Forest Products Laboratory. 15 p. 1996.

FOREST PRODUCTS LABORATORY. Wood handbook: wood as an engineering material. Washington: USDA/FS, 1987. 466 p. (Agriculture Handbook, 72).

HAN, G. S. et al. Composites of wood and polypropylenes III. Mokuzai Gakkaishi, v. 35, p. 1100-1104, 1989.

KOLMANN, F. F. P.; KUENZI, E. W.; STAMM, A. J. Principles of wood science and technology: wood based materials. New York: Springer-Verlarg, v. 2, 1975.

MALONEY, T. M. Modern particleboard \& dry-process fiberboard manufacturing. San Francisco: Miller Freemann, 1993. 696 p.

MOSLEMI, A. A. Particleboard: materials. Carbondale: Southern Illinois University Press, 1974. v. 1. 244 p.
OKSMAN, K.; CLEMONS, C. Mechanical properties and morphology of impact modified polypropylene - wood flour composites. Journal of Applied Polymer Science, v. 67, p. $1503-1513,1998$.

SIMONSEN, J.; JACOBSON, R.; ROWELL, R. Properties of styrene-maleic anhydride copolymers containing woodbased fillers. Forest Products Journal, v. 48, n. 1, p. 89-92, 1998.

WANAGE, H. Y. et al. Effects of D-PVC content on properties of wood particle/plastic composite board. China Wood Industry, v. 12, n. 3, p. 6-9, 1998.

YAN, K. L. et al. Composites from campaunding wood fibers with recycled high density polyethylene. Polymer Engineering and Science, v. 30, n. 11, 1990.

YOUNGQUIST, J. A. et al. Mechanical and physical properties of air-formed wood-fiber/polymer-fiber composites. Forest Products Journal, v. 42, n. 6, p. 42-48, 1992. 